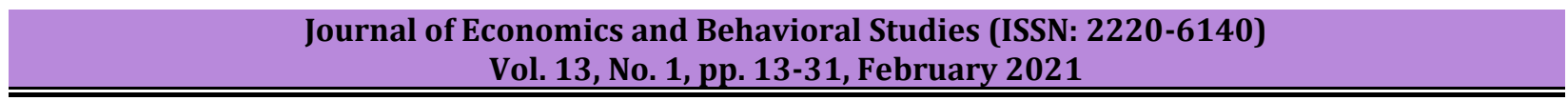

\title{
The Influence of Empathy on Moral Judgments
}

\author{
Rojhat Avsar, Rami Gabriel \\ Columbia College Chicago, Department of Humanities, History, and Social Sciences, USA \\ ravsar@colum.edu,rgabriel@colum.edu
}

\begin{abstract}
Empathy is expected to correlate with pro-social attitudes, but what effect does empathy have on judgments of distributive fairness? In our study, we found that participants with higher empathy scores on the Interpersonal Reactivity Index (IRI) were more likely to: (a) favor the use of egalitarian distribution when the joint effort is involved, and (b) deem overly self-interested or opportunistic behavior unfair. Female participants were more consistent in the exercise of moral judgments across diverse scenarios. Furthermore, empathy has several dimensions (e.g., perspective-taking or empathetic concern) and we observed that they interacted with gender and the nature of the hypothetical problem differently in some cases. Although the findings of the study are not counterintuitive, it has identified some avenues for further explorations and highlighted some potential methodological shortcomings of the IRI as a measure of empathetic traits.
\end{abstract}

Keywords: Empathy, perspective taking, fairness, gender, distributive justice, social norms.

\section{Introduction: How does Empathy Inform Judgments of Fairness?}

Do we decide what's fair based upon our reasoned judgments or our emotional reactions? This distinction is of paramount importance for our notions of responsibility, our appraisal of a person's character, and the functioning of our legal system. In fact, since social and communal interaction by a set of individuals is the very project of civilization, this question intrigued early political philosophers. During the Enlightenment, emotions were considered uncontrollable passions that distort reasoning or forces that weaken the flourishing of the will. Some philosophers focused on the moral and ethical nature of emotions, and how these forces played out in our forms of social organization. A clear understanding of empathy and its neural correlates bears upon larger questions of morality and social living (De Oliveira-Souza, Zhan \& Moll, 2014). In this paper, we describe findings from an empirical investigation of how empathetic traits redound to notions of fair distribution and opportunism in economic exchange. Judging the fairness of any given act engages the emotional experience of empathy. It thus serves as a crucial locus of our interpretation of behavior and subsequent actions.

Yet, there may be a fundamental difference between our knowledge of external objects, our self-knowledge and our knowledge of others (Zahavi, 2014), and when we enter the realm of ethics, judgments of fairness may not be reducible empathy (Thompson, 2005). We will argue Empathy (see review, Cuff, Brown, Taylor \& Howat, 2014) as manifested in personality traits has an effect on ethical decisions. Empathic processes consist of a complex set of interactions between cognitive and affective components (Heberlein \& Saxe, 2005; Strayer, 1987) ${ }^{1}$. Empathy is best thought of as a set of processes, from evolutionarily earliest in affective states to the latest in linguistically-shaped descriptions. Perception of another person's emotional state or perspective-taking, i.e. putting one in someone else's shoes, generally activates one's feelings (though there are differences in brain activity, see Preston et al., 2007). Since it captures the range, function, and phenomenology of the phenomenon. We sponsor a view of empathy forged by animal ethologists like Preston

${ }^{1}$ Cuff et al. (2014) put forward the following definition:

Empathy is an emotional response (affective), dependent upon the interaction between trait capacities and state influences. Empathic processes are automatically elicited but are also shaped by top-down control processes. The resulting emotion is similar to one's perception (directly experienced or imagined) and understanding (cognitive empathy) of the stimulus emotion, with recognition that the source of the emotion is not one's own (p. 7). 
\& de Waal (2002) who considered the evolutionarily earliest form of empathy processes to be 'emotional contagion, a type of affective resonance.

Where an individual (unconsciously, and possibly through subtle nonverbal cues) picks up the emotion of people around her (think for example of how infants take on the emotions of their caregiver). The next layer is the ability to cognitively (and usually consciously) empathize with another creature. The third, and most abstract layer, is the ability to consciously take the perspective of another creature (De Waal, 2007). A reasoned judgment is always based upon the facts of the case, and some cases include more emotional facts than others. One recent model suggests empathy consists of four components: (1) a type of affective sharing based on perception-action coupling, (2) a judgment of the distinction and relation between self and other, (3) a type of mental flexibility which allows the ability to adapt the perspective of another, and finally, (4) empathy as a form of regulating one's own emotions in a social scenario (Decety, 2007; Decety \& Michalska, 2010). Decety et al. argue that there are at least three different types of empathy, cognitive empathy, affective sharing (i.e. emotional contagion), and prosocial motivation (Decety \& Jackson, 2004; Decety \& Cowell, 2014). Another model suggests empathy is a type of simulation, where the act of imagination of what it might be like to be in the situation another person is in is a cognitive simulation. Whether it is simply the affective resonance of matching emotional state, or a conscious act of trying to understand what it is like to be someone else, feeling empathy for someone changes the reasoning process. Reasoning about fairness in the case of in-group members is different, i.e. more empathetic, judgment than reasoning about non-group members.

The three-layered empathy complex we espouse probably evolved for allowing social animals to interact within-group conspecifics (Thompson, 2005). Do we experience empathy more, or only in, our interactions with members of our own in-group? This would suggest that making decisions regarding fairness feels different, i.e. generates empathy, only in certain cases. If this were true, then making a judgment about fairness concerning two individuals in the same situation, say your cousin who is being sentenced for drunk driving, and someone on the other side of town who is being sentenced for the same crime will feel different for you. The in-group-out-group bias reflects the empirically substantiated tenet that Individuals tend to treat members of their in-group in a more egalitarian fashion relative to members of out-groups (Eferson, Lalive \& Fehr, 2008). Larger questions arise as well, like how large can one's in-group be? Is it more accurate to say there are concentric circles of in-groups, say from the brotherhood of man to ethnic groups, neighbors, and family? If so, is there a continuum of feelings of empathy, from a little blip for making a judgment of fairness for someone who went to the same high school to someone who likes the same hockey team to surges of empathy for intimate friends (Dunbar, 1998; de Waal, 1996)? Now that we have some clarity on the role of empathy, how can we characterize reasoned judgments, i.e. judgments based on critical comprehension and subsequent logical contemplation which result in decisions followed by actions? Such judgment must be based on the facts of the case.

For example, what are the reasons given for such action, what is the context, at what time did the action take place, etc. Beyond the facts upon which the judgment is made, there are the prospective implications of making the judgment. For example, being asked to gamble a hypothetical amount of 'money in a psychology experiment is very different from gambling with real rupees in a card game. Prospective implications often frame the reasoned judgment; it is a part of the set of pertinent facts albeit emotional and imaginative. Maybe a more accurate question is: are emotions, like empathy, the same kind of facts to be considered as other kinds of facts, like the causes and consequences of a given act? Does a hint of empathy affect the reasoned judgment as much as a simple fact about the case, such as whether the crime being judged took place during the day or the night? Therefore, a decision concerning fairness is always dependent upon the level and type of emotion that informs the reasoned judgment being made. It turns out our colloquial descriptions of reason have yet to take in the psychological evidence that emotion is one of the rivers that flow into the lake of Reason (Damasio, 1994). It is a river of swirling currents that transport the black soot down from the mountain and divulges an inordinate fertility to the contemplative field. We believe that economic behavior is not satisfactorily captured by the rationality paradigm and is in fact driven by a set of complex motivations, such as empathetic notions of fairness. Accordingly, this study investigates whether empathetic traits predict moral judgments in a set of hypothetical scenarios. In the next section, we discuss how economists have addressed this aspect of economic decisions. 


\section{Complexity of Economic Motivation}

Economists describe individual differences through the concept of diversity in "preferences." They seek to model moral judgments that consider idiosyncratic variations across individuals. According to the approach popularized by Gary Becker (1976), differences in value judgments could simply be explained as differences in "taste." It is not inconceivable that certain "types" emerge when individuals are put in a choice situation in which economic incentives are modified by moral considerations. Modeling the possible heterogeneity of moral types attracted the scholarly attention of economists of experimental leanings. For instance, though there is always fluidity across these categories modified by the context, in Public Good games, it is possible to identify some individuals as "altruists" (i.e. those who contribute to the common pool generously) or "reciprocals" (i.e. those who contribute to the common pool as long as others are doing it) based on their reactions to the scenarios. That is to say, personality types have empirical effects when tested through scenarios. In this study, we are particularly interested in the notion of "fair" distribution and "socially appropriate" (or moral) behavior. In distributing resources, fairness or social propriety can take on several meanings. Sometimes, it is the equal split that resonates as fair; we call this "egalitarian." At other times, merit-based considerations dominate, and these results in a type of distribution we call "utilitarian'." Egalitarian distributions are not sensitive to either difference in skills or the productive contribution of the parties involved.

While utilitarian distributions favor an accounting method that prioritizes productivity above all other potential considerations. It is of course possible that any given individual's moral judgment consists of elements of both egalitarian and utilitarian types, depending on the case of in-group favoritism. Further, it is reasonable to expect fairness considerations to be sensitive to social context and display some (but not complete) convergence when additional information is provided about the circumstances of potential recipients in a resource-distribution scheme. Experimental findings from Frohlich, Oppenheimer, \& Eavery (1987), Faravelli (2007), Cappelen et al. (2007), Côté, Piff, and Willer (2013) among others, appear to corroborate our expectation about a potential convergence in moral judgments when the participants are primed to feel more empathetic. Côté, Piff, and Willer (2013) showed that disinterested upper-class participants (recruited through MTurk as we did) whose judgments were originally geared toward maximizing the total gains irrespective of its effects on the least advantaged ("lose member") in a resource distribution game would be no more utilitarian than their lower-class counterparts once empathy was induced $^{3}$. Frohlich and his colleagues (1987) found that a choice maximizing the average income with a floor that prevents extreme destitution in distribution is most likely. Particularly when participants are not given all the necessary information or asked to reach a consensus.

Faravelli's (2007) results are comparable: Rawlsian minimax (as opposed to egalitarian or utilitarian) in evaluating the fairness of various resource distribution outcomes is the prevalent choice of participants majoring in economics. More interestingly, if when the differences in productivity are explained in terms of circumstances beyond the control of the individual (e.g. in the case of an injury incurred), the Rawlsian choice becomes much more likely. In a clever experimental setting (a dictator game preceded with a production stage), Cappelen and his colleagues (2007) allowed participants to tease out how fairness judgments come about as a result of an interplay between considerations of equity and egalitarian instincts. Although they reported a significant plurality of fairness ideals among the participants, the "liberal egalitarian" position that, of the options available, is the most sensitive to factors out of an individual's control (e.g. luck) appears to be the choice of the majority participating in the experiment. How do we come to decide what we think is fair? Is

${ }^{2}$ Utilitarianism, in the Benthamite sense of the term, not the later iterations, could result in equal distribution justified by the declining marginal utility of income. We use the term in the way in which it is commonly understood/interpreted in economic literature today that finds its clearest expression in the marginal productivity theory of distribution: allocating more resources to the higher productivity individuals maximize the total pie. A merit-blind distribution, on the other hand, creates disincentives, as the argument goes.

${ }^{3}$ The authors had the upper-class participants read the following instructions before they played the game: "As you make your decision, think about the feelings and the wellbeing of the 'lose member' of the group. Concentrate on trying to imagine how the 'lose member' feels and how your decision will influence him or her. Try to feel the impact of your decision on how the 'lose member' of your group will feel." 
it the context of the scenario or the individual's upbringing that determines their notion of fairness? What is the role of personality factors in judgments of fairness? We posit that the notion of what constitutes fair or socially appropriate behavior must depend as much on our personality traits. In particular (the degree of empathy we feel for others) as it does on the contextual information that potentially affects our sense of worthiness and desert/equity in fairness distribution schemes.

Our study fills in the picture of the interaction between personality factors and information upon which moral judgments of fairness distribution are made since extant studies have not focused exclusively on the impact of empathetic, traits on the sense of egalitarianism. One study conducted by Hoffman and Spitzer (1985) demonstrated the following result: participants could be manipulated to become "greedy", i.e. make distributions based on a utilitarian sense of fairness distribution and thus deviate from egalitarian distribution. This was accomplished by making the first movers in the game, the "controllers," (whose role is identical to a dictator in Dictator Games) believe that they "deserve" their status as the "controller" as opposed to the belief that they landed on this position by mere luck. Whereas in the absence of such a belief of moral authority, participants tend to opt for much more egalitarian distributions. Passing judgment on whether others deserve our generosity depends as much on the perceived worthiness of the potential recipient as it does on our moral authority.

Fong (2007) investigated how empathetic dispositions interact with the attributes of the object of empathy, like the recipient of welfare transfers. Defined as the desire to help those who are deserving, empathetic responsiveness predicts charitable-giving in a Dictator Game-like setting if the recipient is worthy of their support. In a similar study, Klimecki et al. (2016) found a strong positive relationship between empathetic (self-reported) feelings, when artificially induced by the experimenter, and the size of the offer in Dictator Game settings regardless of the empathetic pre-disposition of the participants. This is not surprising because empathy may be modulated by various factors such as selective attention, emotional regulation, personal life histories, social distance, etc (Kirman and Teschl, 2010). However, as Klimecki and her colleagues discovered, those who possess emphatic traits responded more strongly to the priming. These participants must have been predisposed "to simulate the internal state" (Singer and Fehr, 2005) of others (e.g., feeling pain) more vividly than their less empathetic counterparts. Forsyth (2019) found that empathetic individuals and tend to be "idealistic" in their moral judgments.

Idealism, as he defines it, represents a strong disposition toward minimizing harm to others. Of the two idealist moral types, empathy, he found, proved to be a strong predictor of "absolutists" who believe that people should act in ways that are consistent with (universal) moral standards. We are also interested in identifying, if available, the differences in the way in which the impact of empathy on moral judgments is mediated by gender as some findings are pointing toward this direction. For instance, if the females are indeed more indiscriminately empathetic (Christov-Moore et al., 2104), some aspects of the scenarios may become more salient to the male participants. In sum, previous studies suggest that an individual's native sense of distributive fairness ranges between egalitarian and utilitarian schemes and that these responses can be modified by manipulating the information upon which decisions are made. We build on some of these earlier findings and expose our participants to a diverse set of hypothetical cases in which they are "provoked" to reveal or express moral judgments. Further, we focus on how personality traits on empathy and in-group favoritism play a role in moral judgments of distribution.

\section{Methods and Hypotheses}

The study we conducted investigates whether being empathetic affects fairness judgments in problems involving, distribution of resources by disinterested individuals. Using Amazon Mechanical Turk (AMT), a crowdsourcing marketplace, we recruited 303 participants of at least high school graduates and asked them to complete an online questionnaire which took participants an average of 26 minutes. ${ }^{4}$ AMT allowed us to

\footnotetext{
4 Eight of the surveys have not been included in the final analysis. Two of them have been discarded since they did not pass the "attention" test where the responses were completely counterintuitive. The rest of the responses have been eliminated in the process of removing outliers. We excluded the empathy scores that lied on the both extremes, too low or too high, relying on the Stem-and-Leaf Plot tool provided by the SPSS statistical software package.
} 
reach larger (considering our limited research budget) and more diverse participants (in terms of age and upbringing) than college students who are customary participants in such studies. The first part of the questionnaire consists of demographic questions (see Table 1). The Interpersonal Reactivity Index (Davis, 1983), a commonly used survey that measures the level of empathy along four equally weighted dimensions: perspective-taking, fantasy, empathic concern, and personal distress.

These constitute our independent variables. Since folk wisdom suggests that moral values are shaped partly by an individual's upbringing, we included the following as part of our demographic questionnaire: Did you have a religious upbringing/childhood? Did either of your parents graduate from college? What kind of area in which you were raised? The second part of the questionnaire asks participants to respond to three scenarios that motivate the exercise of moral judgment and thus serve as our dependent variables (see questionnaire with three scenarios in the appendix). Three scenarios were presented; the first one concerns the fairness of distribution of rewards relative to the distribution of work put in on building a bike. The second scenario is an ultimatum game with the addition of a question about the participant's emotional reaction to the results of the game. The third scenario is about a moral judgment concerning raising prices at a hardware store. (The details of the scenarios are provided in the Appendix.) Participants' empathy scores on the Interpersonal Reactivity Index (IRI) were used to predict their responses to three hypothetical scenarios in a set of logistic regressions and decision trees to test the following hypotheses.

- (Distributive Justice) Hypothesis \#1: Higher empathy scores will be associated with more egalitarian distribution preferences when some favorable information is provided about the circumstances of the disadvantaged individual in our hypothetical productive exchange setting.

- (Social Norm Violations) Hypothesis \#2: Higher empathy scores will increase the likelihood of rejecting the $\$ 2$ offer in the ultimatum game.

- (Moral Limits to Profit) Hypothesis \#3: Higher empathy score will increase the likelihood of finding the decision to raise prices by the hardware store owner unfair.

- (Consistency of Moral Judgments) Hypothesis \#4: Empathetic individuals make consistent choices across all the cases. We define "moral consistency" as maintaining a notion of fairness across scenarios; in this case, it refers specifically to (i) opting for egalitarian distribution, and (ii) calling a $\$ 2$ offer and the decision to raise prices unfairly.

Table 1: Demographic Variables

\begin{tabular}{|c|c|}
\hline 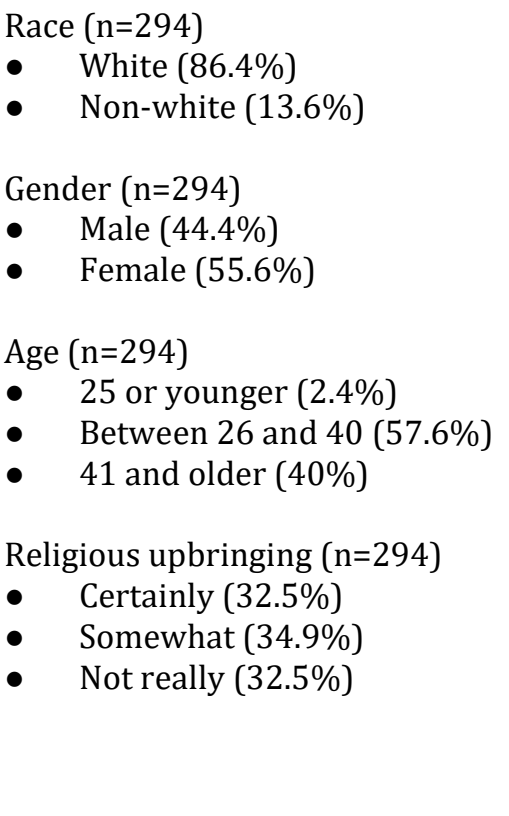 & 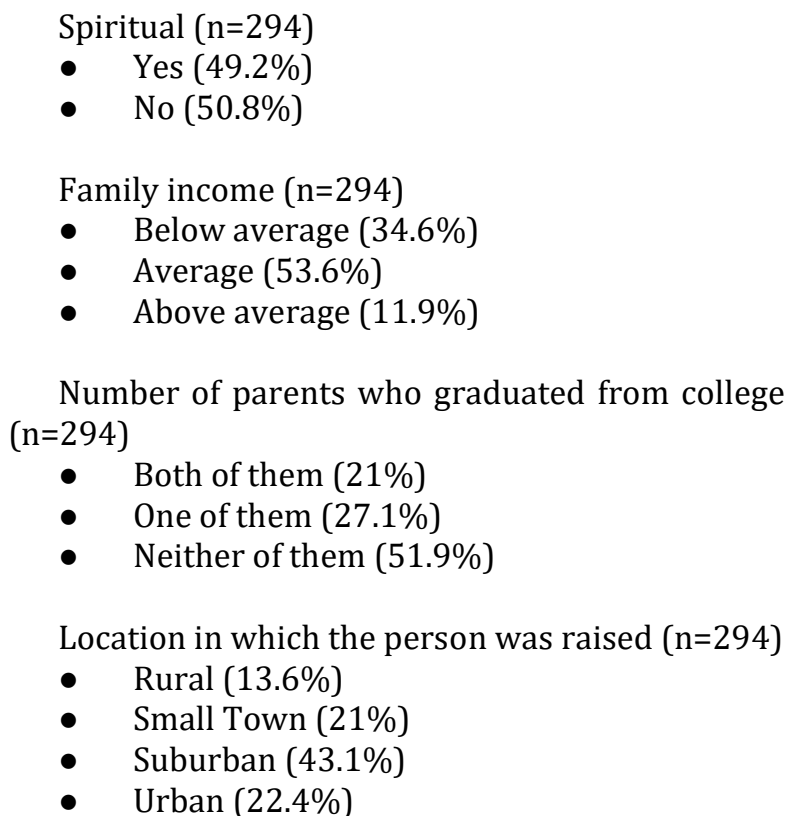 \\
\hline
\end{tabular}


The participants' sense of distributive justice in the real world. Moreover, there are drawbacks to capturing individual traits with aggregated scores because this approach could miss the nuances that may be present in the responses to 28 individual questions (7 under each category) in the IRI. For instance, when we reviewed the empathic concern scale, we noticed there are noticeable inconsistencies: of the seven different questions meant to measure the level of empathic concern, some participants scored very high on some questions while scoring very low on others. The latter strikes us as a more actionable feeling. Another possibility for the apparent inconsistency is that individual questions may measure aspects of personality traits more strongly than they do empathy.

Figure 1: Frequency Distribution - Empathy Scores (min 25; $\max =100)$

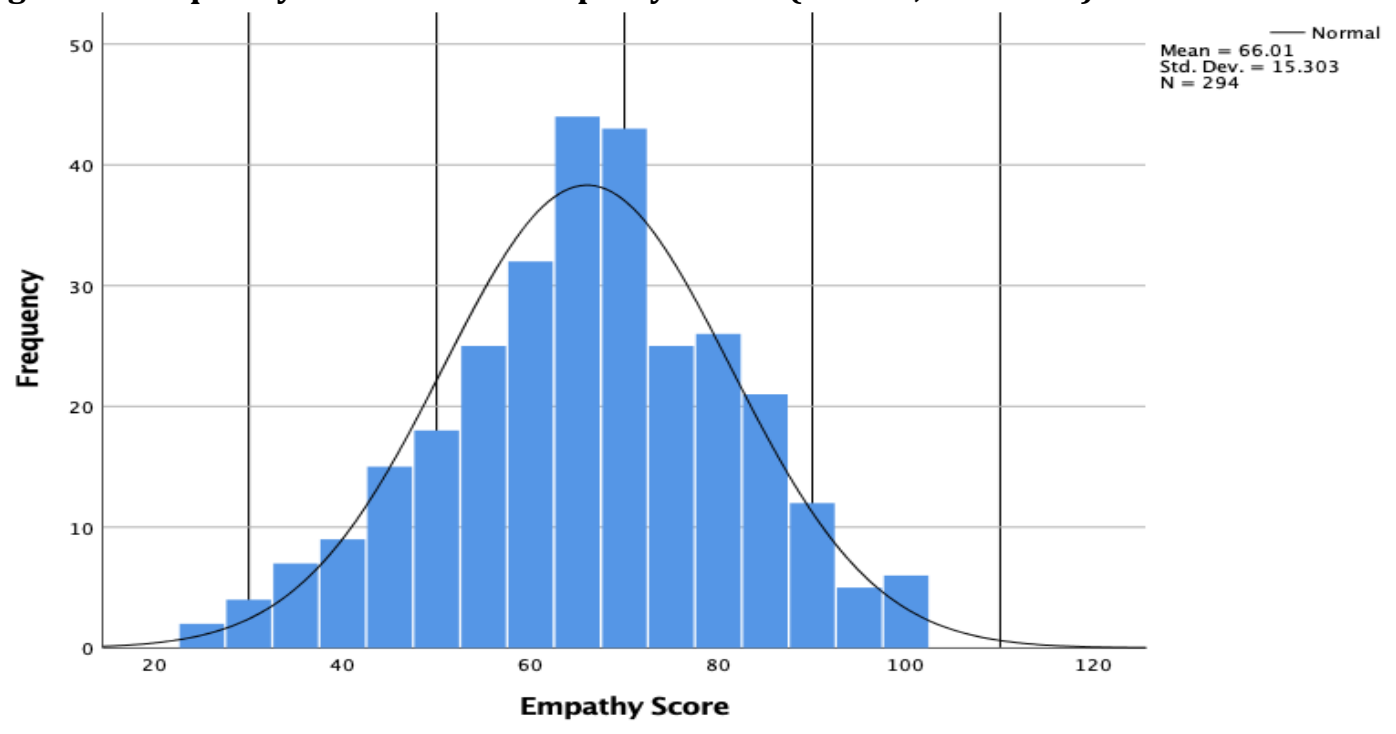

\section{Results}

Result 1: In the first scenario, we investigated how empathy informs the sense of "fair" distribution. We asked participants to distribute collectively produced output between those who contributed to building the bicycle in the scenario. These choices could be described as "egalitarian (4)," "mild egalitarian (3)," "mild utilitarian (2)," and "utilitarian (1)," based on the gap between the respective shares ranging from 0 hours in the one extreme (egalitarian) to 84 hours in the other (utilitarian). Initially, we provided no contextual information about the individuals except that one party had contributed less than the other. The participants made their selections. Then some contextual information is provided about the causes of the productivity differences. We used the Decision Tree with CHAID growing method ${ }^{5}$ to trace if empathy and our demographic variables could explain the change of heart among our participants. We expected that empathetic individuals are likely to opt for a more equal distribution of bike hours once they are told that the productivity differences had been caused by factors beyond the individual's control. Indeed, the additional context changed the odds of opting for Egalitarian distribution, which increased in participants with higher empathy scores. However, the relationship between empathy and the shift toward the egalitarian distribution is true mostly for those who were Mild Egalitarians, to begin with, and not across the board (See Figure 2).

Of those who were mildly egalitarians, those with empathy scores exceeding 53 (which corresponds to the cutoff for the bottom quintile) are more likely to switch their position in favor of a fully egalitarian distribution once some context is provided. It also appears that those who are 41 and older are slightly overrepresented. This result supports our Hypothesis \#1 that empathy increases sensitivity to other people's personal circumstances (in particular, those that are beyond their control) in exercising distributive fairness judgments when the joint effort is involved. This is a unique form of cooperation that Lawler and his

${ }^{5}$ Minimum cases in Parent (the Child) Node is 50 (20). 
colleagues called "productive exchange" (2008). It differs from other forms of exchange like reciprocal trades in its ability to foster a greater degree of group solidarity. That said, the empathy threshold, 53, may have been caused by the fact that our participants appeared already to be fairly egalitarian-minded, a hunch which Table 2 does appear to corroborate to some extent: Around 52 percent of the participants chose Mildly Egalitarian distribution (3) before any context was provided. Interestingly, this group's empathy scores are evenly distributed across each quintile with no apparent indication of empathy being the most significant driver of their decision in the first place. A word of caution is in order here: the fact that invoking empathy in the absence of emotional priming is rather challenging (considering its strong affective dimension) may have caused some underestimation in our study of the actual role that empathy plays in informing.

For instance, "Sometimes I feel very sorry for other people when they are having problems" expresses a more passive/reactive emotional reaction than "When I see someone being taken advantage of, I feel kind of protective towards them." What to make of this? One possibility is that the framing of questions is a determinative factor. This suspicion led us to conduct a two-stage cluster analysis. The results are noteworthy: based on responses to the questions meant to measure Empathic Concern, participants can be grouped into three clusters (See Figure 3). While it is beyond the scope of this paper to speculate if any of the clusters correspond to identifiable personality traits, we should note that compared to the other two Cluster 3 reliably predicted egalitarian choices in the allocation of bike hours with or without the context information. Moreover, its predictive ability is enhanced when it interacts with the "male" gender; i.e. being male and a member of Cluster 3 successfully predicted egalitarian choices.

Table 2: Frequency Distribution - Allocated Bike Hours With and Without Context

\begin{tabular}{lllll}
\hline & Without Context & \multicolumn{3}{l}{ With Context } \\
\hline Types & frequency & percent & frequency & percent \\
egalitarian & $77(12)$ & $26.2\left(15.5^{*}\right)$ & 177 & 60.2 \\
mild-egalitarian & $152(32)$ & $51.7\left(21^{*}\right)$ & 95 & 32.3 \\
mild-utilitarian & $52(11)$ & $17.7\left(21.1^{*}\right)$ & 18 & 6.1 \\
utilitarian & $13(0)$ & $4.4\left(0^{*}\right)$ & 4 & 1.4 \\
\hline
\end{tabular}

* Percentage of those who fall in the top quintile (20\%) of the empathy score distribution 
Figure 2: Empathy and Egalitarian Attitudes

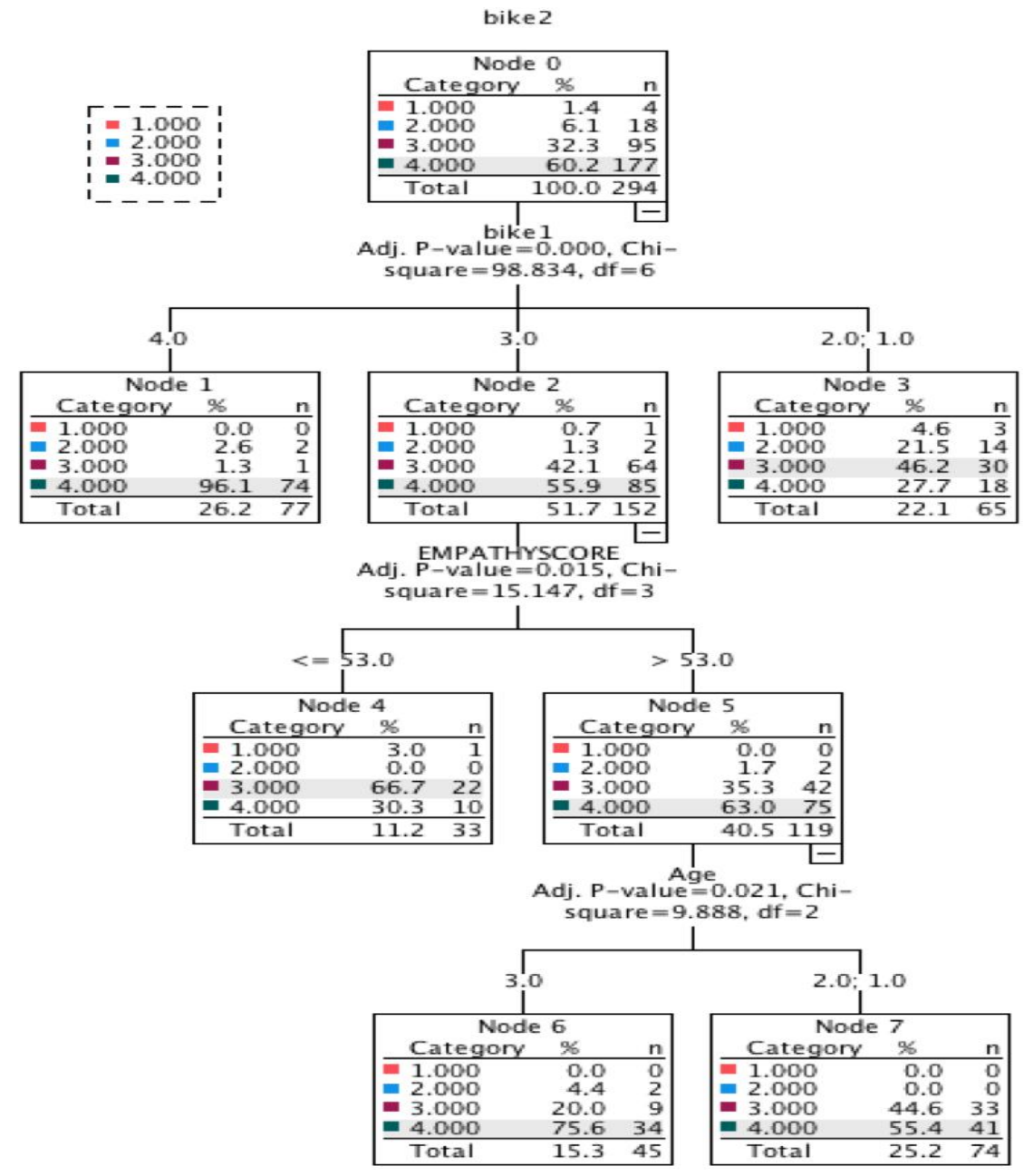




\section{Figure 3: Clusters Based on Empathic Concern Scales Questions ${ }^{6}$}

\section{Clusters}

Input (Predictor) Importance

$\square 1.0 \square 0.8 \square 0.6 \square 0.4 \square 0.2 \square 0.0$

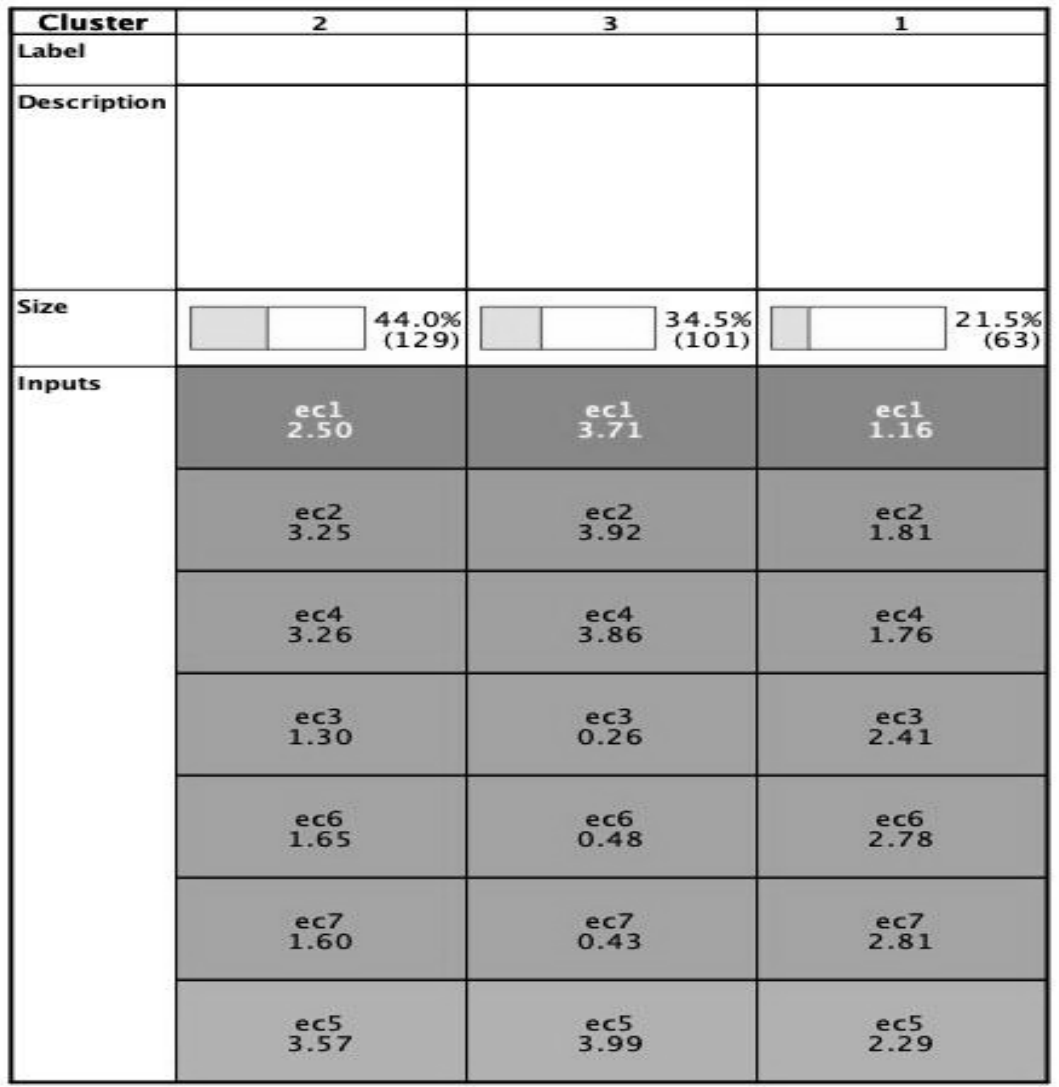

Result 2: In the second scenario, we investigated whether empathetic individuals are more sensitive to norm violations. We asked whether the participants would accept an offer of $\$ 2$ out of $\$ 100$ in a hypothetical ultimatum game-an offer that is clearly too low. The flat fee of $\$ 5$ was offered to the subjects for their participation in the overall study and the fee was not conditioned on their responses. So, we recognize that this feature of our design is a major departure from the typical ultimatum games in the sense that the participants were not forced to "practice what they preach" and have no financial stakes in their decision to reject. However, this deliberate dissociation is consistent with our expectation that participants act like "impartial spectators" even though this setup may have increased the rejection rate. Which we cannot independently verify considering there is no meaningful benchmark study for comparison except the

\footnotetext{
6 (EC1: I often have tender, concerned feelings for people less fortunate than me. EC2: Sometimes I don't feel very sorry for other people when they are having problems. EC3: When I see someone being taken advantage of, I feel kind of protective towards them. EC4: Other people's misfortunes do not usually disturb me a great deal. EC5: When I see someone being treated unfairly, I sometimes don't feel very much pity for them. EC6: I am often quite touched by things that I see happen. EC7: I would describe myself as a pretty soft-hearted person.)
} 
receivers tend to reject offers less than $20 \%$ of the sum $50 \%$ of the time and the rejection rate increases as the share get ever smaller (Houser and McCabe, 2014). That said, we are much more interested in how participants describe such an offer and what their emotional reactions would be than whether they would reject the offer. After making their decision to accept or reject.

We asked the participants to select from a list of attributes describing the personality of the person making the lopsided. We also asked the participant how the offer would make them feel by selecting from a list of descriptive emotions. In the binomial logistic regression that we conducted, there is no statistically significant relationship between the individual's empathy score and the likelihood of rejecting the $\$ 2$ offered $(\mathrm{p}=0.363)$. The results do not support our hypothesis (\#2) that a higher empathy score is correlated with a higher likelihood of rejecting a very low offer. However, as Decety and Cowell (2014) argue, the relationship between morality and empathy is complex and nuanced; and the neural correlates of, say, empathetic concern differ in significant ways from those of, say, perspective-taking. Therefore, following their recommendations, we have decided to distinguish between the different facets of empathy as each facet might influence moral judgments somewhat uniquely. We disaggregated the empathy index into its constituent components. One of the four constituents of the aggregate empathy index on the IRI, the Perspective Taking (PT) score alone appears to have successfully predicted $(p=0.008, \operatorname{Exp}(B)=1.134)$ the odds of rejecting the offer at a $1 \%$ significance level. Only a one-point increase in one's PT score increases their odd of rejecting.

The offer by 1.134 , a very substantive effect (See Table 3 ). This may be because the scenarios employed in the study are abstract and participants do not experience empathy with the vivacity of the more ecologically valid lived scenario. Our result supports our expectation that taking the perspective of the offender (to figure out their intention) as well as that of the offended would aid in detecting social norm violations and reinforcing reciprocal punishments. Moreover, we are curious whether the different facets of empathy interact with gender. Our expectation is that when modified by gender some of the subcategories of empathy categories can successfully predict the odds of rejecting the offer. We have rather intriguing results. Although Perspective Taking is explanatory regardless of the gender ${ }^{7}$, Empathic Concern $(p=0.043$; Exp $(B)=0.839)$ and Personal Distress $(\mathrm{p}=0.029$; $\operatorname{Exp}(\mathrm{B})=0.880)$ scales are significant (and so in non-negligible ways) only when they interact with gender. Specifically, EC increases one's likelihood of rejecting the offer if they are male, while Personal Distress increases one's likelihood of rejecting the offer if they are female! (See Table 4) Christov-Moore et al. (2014) found such gender effects in empathy-related judgments to be common in the literature and suggest compelling explanations for such implicit differences. They discuss evolutionary considerations of caring instincts but also make room for developmental differences, neural differences, and socialized gender roles. In the second stage of the study, we allowed the participants to choose from a list of descriptions that characterize what they think of the person who offered $\$ 2$.

We used the Decision Tree approach with the CHAID growing method as it is very conducive to revealing interaction among independent variables in a clearly interpretable visual fashion. Calling the proposer "Unwise" appeared to be the strongest predictor of rejecting the offer. For those who did not choose to select "Unwise," "Unfair" was the strongest predictor of rejection. Interestingly, the impact of "Unfair" has been modulated by the participants' PT score: among those who called the proper "Unfair," those with the PT score higher than 21 (out of possible 28 ) nearly unanimously (95.7\%) rejected the offer. What about the emotional reactions? Of the emotional categories provided, "Angry" $(87.6 \%)$ is the strongest predictor of whether someone penalized the proposer, by rejecting the meager offer even though it would have made them $\$ 2$ better off than before. The role of anger in rejections of low offers in UGs was also corroborated by a smallerscale study by Bosman, Sonnemans, and Zeelenberg (2001) who found that the intensity of "anger" that the participants said they felt to be negatively correlated with the level of offers. Moreover, they found that, for those who rejected, anger along with "irritation" and "contempt" were the most strongly felt emotions evoked by the low offer. In our study, interestingly, anger also interacted with gender: among those who describe their primary emotion as "Angry" in reaction to the proposed amount, female participants rejected the offer to a greater degree ( $92.6 \%$ vs. $81.9 \%$ for males). Of those (female or male) who did not select "Angry," the emotion, "Frustrated," appeared to be a strong predictor of rejection (75.3\%).

${ }^{7}$ Although not included in Table 4, when PT interacts with gender it comes out significant for both genders. 
Table 3: Rejection of Low Offers and Perspective Taking

Dependent Variable: Rejection (=1)

\begin{tabular}{|c|c|c|c|c|c|c|}
\hline & $\mathrm{B}$ & S.E. & Wald & $\mathrm{df}$ & Sig. & $\operatorname{Exp}(B)$ \\
\hline Race $($ Non-white $=1)$ & .490 & .428 & 1.307 & 1 & .253 & 1.632 \\
\hline Gender (Female = 1) & .008 & .321 & .001 & 1 & .981 & 1.008 \\
\hline Age (young) & & & 3.736 & 2 & .154 & \\
\hline Age(mid-aged) & -.332 & .864 & .148 & 1 & .701 & .717 \\
\hline Age(old) & .576 & .331 & 3.039 & 1 & .081 & 1.780 \\
\hline Religious (certainly) & & & 1.200 & 2 & .549 & \\
\hline Religious (somewhat) & -.425 & .398 & 1.138 & 1 & .286 & .654 \\
\hline Religious (not really) & -.295 & .372 & .629 & 1 & .428 & .745 \\
\hline Spiritual (Yes =1) & -.003 & .327 & .000 & 1 & .994 & .997 \\
\hline Income (Below Avg) & & & 1.294 & 2 & .524 & \\
\hline Income (Average) & .553 & .487 & 1.291 & 1 & .256 & 1.739 \\
\hline Income (Above Avg) & .404 & .457 & .780 & 1 & .377 & 1.498 \\
\hline Parents (No College) & & & .590 & 2 & .745 & \\
\hline Parents (One College) & -.010 & .376 & .001 & 1 & .980 & .990 \\
\hline Parents (Both College) & .270 & .433 & .391 & 1 & .532 & 1.310 \\
\hline Location (rural) & & & 2.396 & 3 & .494 & \\
\hline Location (s town) & .373 & .546 & .466 & 1 & .495 & 1.452 \\
\hline Location (suburb) & -.329 & .431 & .582 & 1 & .446 & .720 \\
\hline Location(urban) & .168 & .387 & .187 & 1 & .665 & 1.183 \\
\hline PERSONAL DISTRESS & .056 & .044 & 1.644 & 1 & .200 & 1.058 \\
\hline PESPECTIVE TAKING & .126 & .048 & 6.959 & 1 & .008 & 1.134 \\
\hline EMPATHIC CONCERN & .098 & .071 & 1.916 & 1 & .166 & 1.103 \\
\hline FANTASY & -.051 & .049 & 1.078 & 1 & .299 & .950 \\
\hline Constant & -4.053 & 1.777 & 5.203 & 1 & .023 & .017 \\
\hline
\end{tabular}


Table 4: Rejection of Low Offers when Different Empathy Categories Interact with Gender

Dependent variable: Rejection ( $=1)$

\begin{tabular}{|c|c|c|c|c|c|c|}
\hline & B & Std. Error & Wald & Df & Sig. & $\operatorname{Exp}(B)$ \\
\hline Intercept & 3.704 & 1.847 & 4.022 & 1 & .045 & \\
\hline Age (young) & .134 & .906 & .022 & 1 & .883 & 1.143 \\
\hline Age(mid-aged) & -.675 & .339 & 3.962 & 1 & .047 & .509 \\
\hline Age(old) & $0^{\mathrm{b}}$ & . & . & 0 & . & . \\
\hline Religious (not really) & .489 & .407 & 1.446 & 1 & .229 & 1.631 \\
\hline Religious (somewhat) & .336 & .376 & .798 & 1 & .372 & 1.400 \\
\hline Religious (certainly) & $0^{\mathrm{b}}$ & . & . & 0 & . & . \\
\hline [Spiritual = NO] & -.092 & .334 & .075 & 1 & .784 & .912 \\
\hline [Spiritual= YES] & $0^{\mathrm{b}}$ & . & . & 0 & . & . \\
\hline Income (Below Avg) & -.474 & .496 & .914 & 1 & .339 & .622 \\
\hline Income (Average) & -.348 & .463 & .567 & 1 & .451 & .706 \\
\hline Income (Above Avg) & $0^{\mathrm{b}}$ & . & . & 0 & . & . \\
\hline Location (rural) & -.460 & .556 & .684 & 1 & .408 & .632 \\
\hline Location (s town) & .307 & .441 & .486 & 1 & .486 & 1.360 \\
\hline Location (suburb) & -.187 & .392 & .228 & 1 & 633 & .829 \\
\hline Location(urban) & $0^{\mathrm{b}}$ & . & . & 0 & . & . \\
\hline Parents (No College) & -.099 & .385 & .066 & 1 & .797 & .906 \\
\hline Parents (One College) & -.340 & .437 & .606 & 1 & .436 & .711 \\
\hline Parents (Both College) & $0^{\mathrm{b}}$ & . & . & 0 & . & . \\
\hline$[$ Race $=$ White $]$ & -.547 & .436 & 1.576 & 1 & .209 & .579 \\
\hline$[$ Race $=$ Non-white $]$ & $0^{\mathrm{b}}$ & . & . & 0 & . & . \\
\hline PESPECTIVE TAKING & -.127 & .049 & 6.736 & 1 & .009 & .881 \\
\hline$[$ Gender $=0$ ] * EC & -.175 & .087 & 4.079 & 1 & .043 & .839 \\
\hline$[$ Gender $=1] *$ EC & -.020 & .093 & .048 & 1 & .827 & .980 \\
\hline$[$ Gender $=0] * \mathrm{PD}$ & .043 & .068 & .392 & 1 & .531 & 1.044 \\
\hline [Gender $=1] *$ PD & -.128 & .059 & 4.775 & 1 & .029 & .880 \\
\hline$[$ Gender $=0] * \mathrm{FS}$ & .038 & .072 & .272 & 1 & .602 & 1.038 \\
\hline$[\text { Gender }=1]^{*} \mathrm{FS}$ & .081 & .061 & 1.743 & 1 & .187 & 1.084 \\
\hline
\end{tabular}


Figure 4: Describing the Person offering \$2 and Likelihood of Rejecting

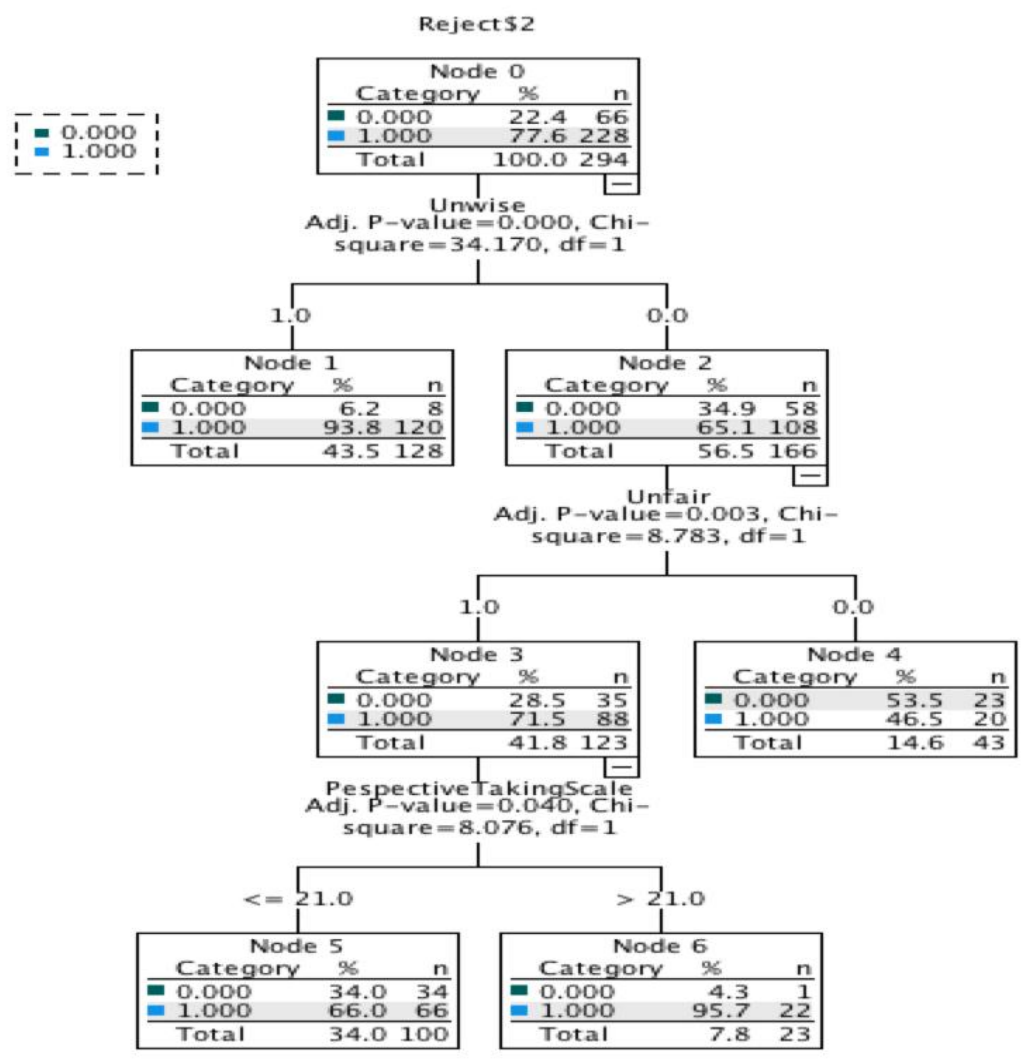

Figure 5: Emotional Reactions to the Low Offer and Likelihood of Rejection

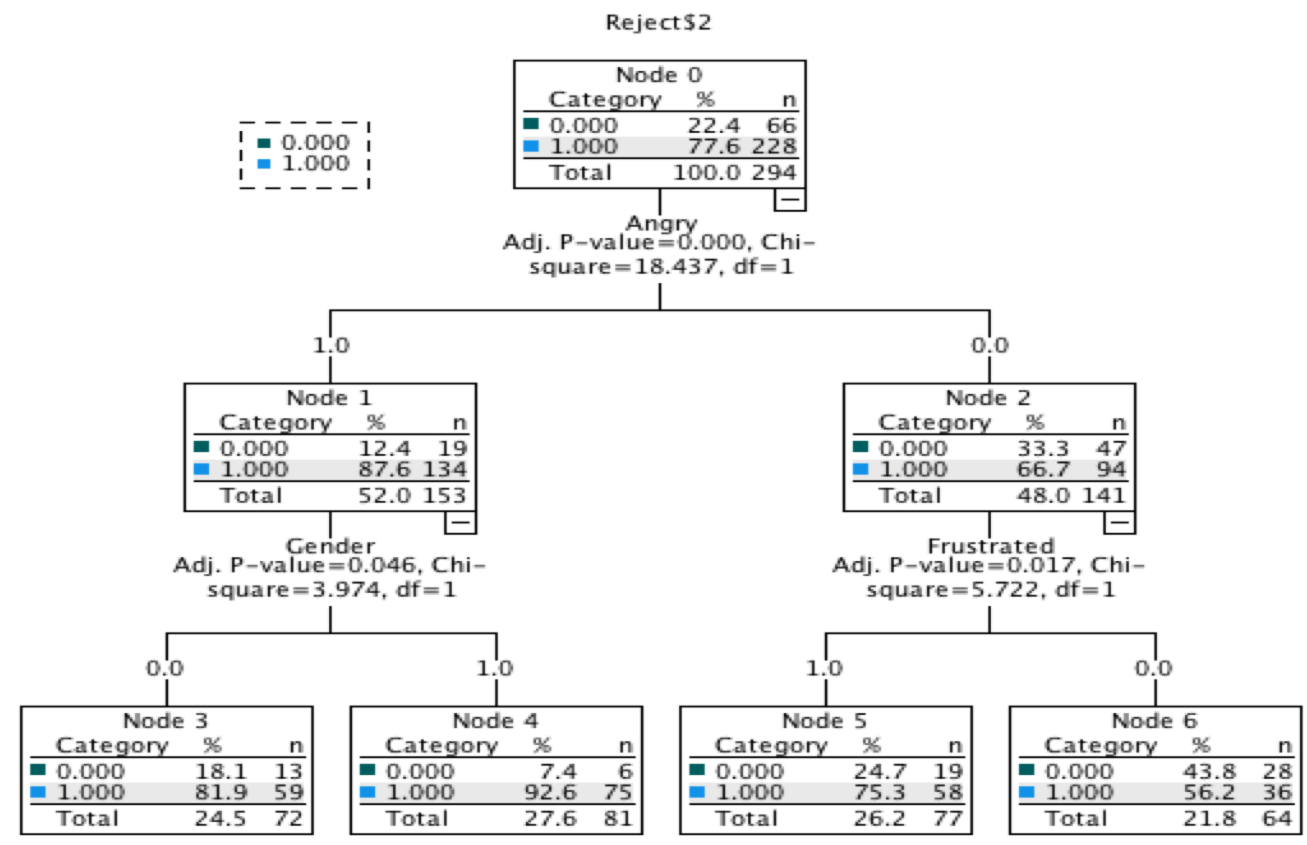


Result 3: In Case 3, we investigated whether participants would consider opportunistic market behavior as unfair or just as another incidence of supply-demand interaction. Moral limits to markets like price gouging laws are commonplace, and we hoped this scenario would help capture our participants' attitude toward the acceptability of such constraints on profit-making. We expected that the higher the empathy level the lower the tolerance for opportunistic behavior of the type described here. In the multinomial logistic regression that we conducted, Empathy Score does appear to differentiate those who find this behavior "unfair" from those who consider it a fair game $(p=0.024, \operatorname{Exp}(B)=0.978)$. Therefore, a higher empathy score on the IRI increases the likelihood of finding the decision to raise prices unfairly ${ }^{8}$. Some demographic variables also appear significant for this question; for instance, male participants $(p=0.002$, $\operatorname{Exp}(B)=2.466)$ are nearly two and a half times more likely to find the decision to raise the prices fair (compared to unfair) compared to their female counterparts. Strikingly, male participants are more than four times more likely to opt for "does not apply" versus "unfair." Perhaps this reflects their inclination to see opportunism as all part of the game $(p=0.003, \operatorname{Exp}(B)=4.360)$. Having grown up in a rural area (compared to an urban area) along with those who described their upbringing environment as "Somewhat Religious" (compared to "Certainly Religious") do appear to increase the likelihood of finding the business practice of raising prices in the hardware store scenario unfair $(\mathrm{p}=0.008, \operatorname{Exp}(\mathrm{B})=0.220)$.

Table 5: Hardware Store Case (The reference category: unfair)

\begin{tabular}{|c|c|c|c|c|c|c|}
\hline 0 & B & Std. Error & Wald & $\mathrm{df}$ & Sig. & $\operatorname{Exp}(B)$ \\
\hline Intercept & 1.324 & .964 & 1.887 & 1 & .170 & \\
\hline EMPATHYSCORE & -.022 & .010 & 5.096 & 1 & .024 & .978 \\
\hline [Gender = Male $]$ & .903 & .297 & 9.221 & 1 & .002 & 2.466 \\
\hline$[$ Gender $=$ Female $]$ & $0^{\mathrm{b}}$ & . & . & 0 & & . \\
\hline [Religious = Not really $]$ & -.288 & .360 & .642 & 1 & .423 & .750 \\
\hline [Religious = Somewhat] & -.775 & .342 & 5.128 & 1 & .024 & .461 \\
\hline [Religious = Certainly $]$ & $0^{\mathrm{b}}$ & . & . & 0 & . & . \\
\hline [Location = RURAL] & -1.514 & .573 & 6.991 & 1 & .008 & .220 \\
\hline [Location = STOWN] & .393 & .403 & .947 & 1 & .331 & 1.481 \\
\hline [Location = SUB] & .219 & .359 & .372 & 1 & .542 & 1.245 \\
\hline [Location = URBAN] & $0^{\mathrm{b}}$ & . & . & 0 & . & . \\
\hline 1 & B & Std. Error & Wald & $\mathrm{df}$ & Sig. & $\operatorname{Exp}(B)$ \\
\hline Intercept & -.981 & 1.486 & .435 & 1 & .509 & \\
\hline EMPATHYSCORE & -.005 & .016 & .101 & 1 & .751 & .995 \\
\hline [Gender = Male $]$ & 1.473 & .492 & 8.964 & 1 & .003 & 4.360 \\
\hline [Gender = Female] & $0^{\mathrm{b}}$ & . & . & 0 & & \\
\hline
\end{tabular}

${ }^{8}$ However, empathy score on the IRI does not help predict the response of those who thought that the situation should not be evaluated within the fair vs. unfair dichotomy (i.e. those who selected "fairness does not apply")

${ }^{9}$ Of the control variables, only those that are significant at the $5 \%$ were reported. 
Result 4: Finally, we were curious whether judgments exercised across these three relatively diverse cases have any common denominator. Accordingly, we created a variable to measure moral consistency in the local sense. By our definition, the variable of 'morally consistent' applies to individuals who (i) opted for the egalitarian distribution in our first case after the context is provided; (ii) found $\$ 2$ offer unfair in the UG; and (iii) found the hardware store owner's decision to raise the price unfairly. Each aspect is equally weighted with the participant allotted one point if the condition is true. The highest possible score, the sign of moral consistency, is three (3) points. We should note that getting zero total points could be a form of consistency in the negative sense, i.e. to be morally consistent but non-egalitarian. However, the number of participants in this category is negligible (2.4\%).10 Based on the results of our multinomial regression we can make the following observation: female gender when coupled with higher empathy score is a reliable predictor of moral consistency in our study - a pattern that does not seem to carry over to those whose income is above average. Again, we refer the reader to Christov-Moore et al. (2014) for a multi-causal explanation of why empathy judgments consistently vary according to gender.

Table 6: Moral Consistency and its Determinants

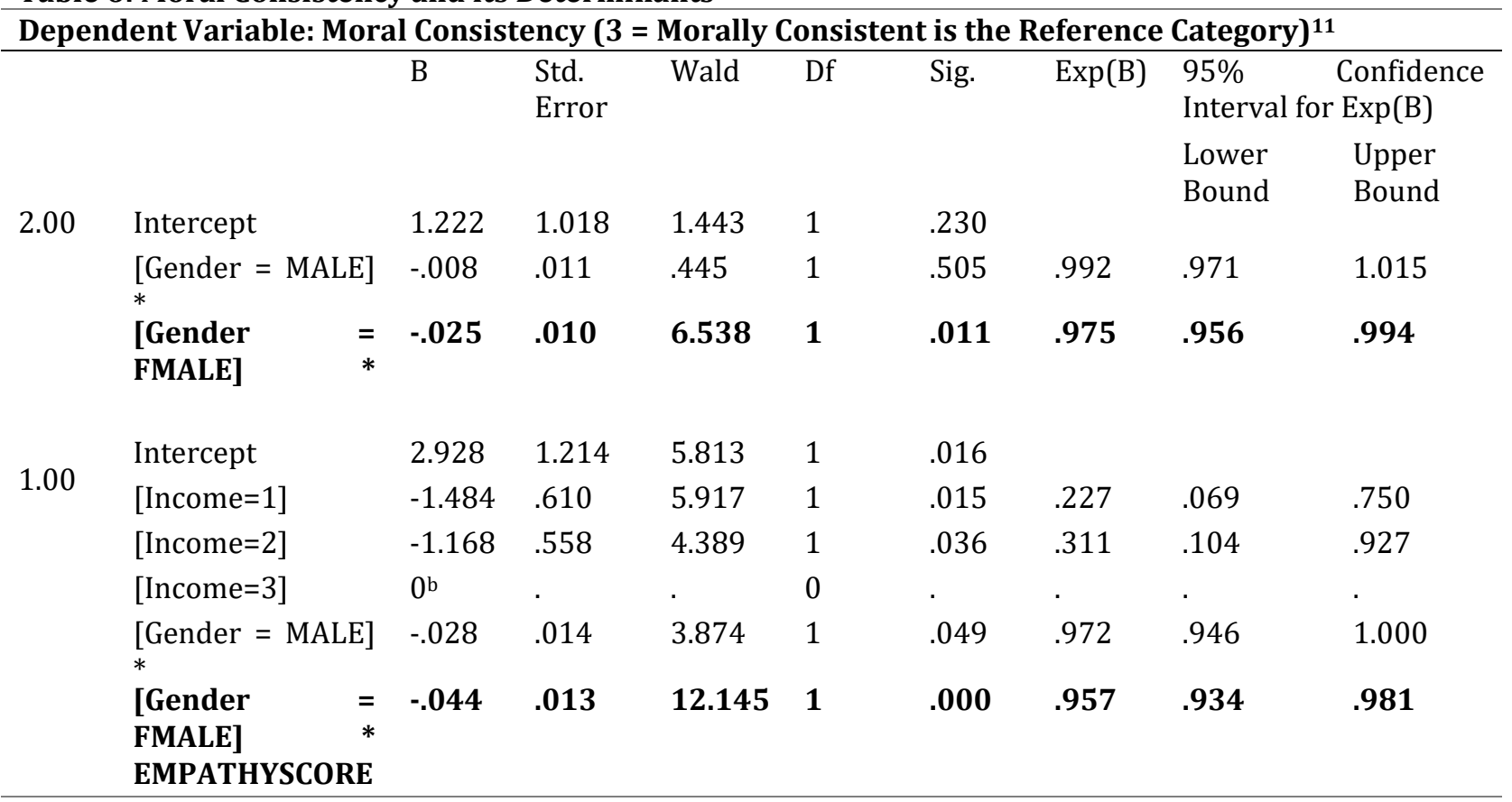

\section{Discussion}

Our results lend themselves to several interpretations. First, empathy tends to favor egalitarian distribution if the context provided suggests that circumstances in the scenario are depicted as being beyond the individual's control. Secondly, empathetic individuals display context-sensitivity in exercising fairness judgments. When empathy is measured as perspective-taking, our results indicate empathetic individuals are more sensitive to deviations from social norms and more likely to exercise negative reciprocity in the face of unfair (or anti-social) treatment as evidenced by their reactions in the ultimatum game. This may be because they are taking an explicit ethical position to an abstract scenario and then simulating the consequences, this may also be a form of virtue signaling. Why does one's ability to take the perspective of another increase their chances of rejecting the lopsided offer in the ultimatum game? Of the terms that participants chose to describe the lopsided split in the ultimatum game, three of them successfully predicted (at .01 significance) whether or not they would reject the offer: "acceptable," $(p=0.005, \operatorname{Exp}(B)=0.031)$ "rational," $(p=0.001$,

${ }_{10}^{10}$ We merged this category, 0 , with 1 in testing moral consistency.

${ }^{11}$ Of the control variables, only those that are significant at the $5 \%$ were reported 
$\operatorname{Exp}(B)=0.062)$ and "unwise" $(p=0.001, \operatorname{Exp}(B)=7.863)^{12}$. Needless to say, the first two are negatively, and the last one positively, correlated with the probability of rejecting the offer. Perspective-taking, an integral element of empathy, may have contributed to the description of the rejected offer as "unwise". This prediction is reinforced by the fact that "unwise" is strongly correlated with the emotions of frustration, sadness, and surprise. A set of emotional words the participants chose to describe the low offer.

Calling the low offer "unfair" was another strong predictor of rejection whose predictive power is even higher for those whose perspective-taking skills are fairly elevated. The low offer seems to be processed as a violation of social norms. Those who rejected the offer in the ultimatum game may have thought: "I would not have done that!" We asked participants to tell us how they feel about being offered so little in the ultimatum game scenario. Those who selected the following emotions were more likely to take the offer: "neutral" $(p=0.001, \operatorname{Exp}(B)=0.089)$, "pleased" $(p=0.011, \operatorname{Exp}(B)=0.048)$ and, interestingly, "jealous" $(p=0.019$, $\operatorname{Exp}(B)=0.242)^{13}$. Anger $(p=0.035, \operatorname{Exp}(B)=2.108)$, on the other hand, appears to have strongly motivated the participants to reject the offer: the odds of rejecting the offer are 2.1 times higher among those who characterized their feelings in this way. It is reasonable to expect that the low offer must have fed the sense of getting unfairly treated based on the high correlation between "anger" and "unfair" ( $p=0.001$, coefficient $=0.389$ ). This is not surprising as anger as an emotion is a potent tool to display discontent and the motivational force behind our push for fairness ${ }^{14}$. Apart from being inequity-averse by rejecting the low offer and, effectively, penalizing the behavior, empathetic individuals are inclined to see overtly self-interested behavior (e.g. raising prices) as unfair. That said, empathy is not the only variable that makes one sensitive. To the opportunistic behavior of pursuing one's interests at the expense of others. Gender and the population density of the location of upbringing also exert influence on one's moral judgments. The latter may be explained by the fact that in sparsely populated regions, social relationships tend to be much less impersonal. Our finding is in line with the findings of Sautter, Littvay, \& Bearnes (2007) that empathy is more likely to result in cooperative behavior among those who were raised in sparsely populated localities due to the diminished, anonymity they experienced growing up. Lastly, we observed a formed consistency in exercising moral judgments among some of our participants. They proved to be Rawlsian compassionates in accommodating the least fortunate in the joint-production scenario, reciprocal in penalizing the norm-deviant in the UG, and, probably, followers of rule-based ethics in our last case (e.g., you shall not take advantage of the circumstances). Such consistency is much more pronounced among female participants with high empathy levels particularly when these two variables interact with income.

\section{Conclusion}

In this paper, we investigated the relation between empathetic personality characteristics measured by the IRI and decisions on a set of distribution scenarios. We found that an individual's Perspective Taking (PT) score on the IRI was a sole predictor of rejecting unfair offers in an ultimatum game. The active element of empathy in this scenario was cognitive empathy which allowed participants to imagine the perspective of the other as a frame to a fairness judgment on a distribution game. The effect of the location of upbringing is evident in our last case and may be explained by the fact that individuals from rural backgrounds have a different sense of responsibility towards in-group members, which then affects how they frame judgments of fairness. Providing context is crucial to adding an affective dimension to an abstract scenario as in case 1. Empathy and context-sensitivity are related psychological elements with the cognitive appraisal of fairness. To get back to our initial question of whether fairness is determined by reason or emotion, we suggest it may be that the effective tug of empathy modulates attentional processes to modify how reason weights

12 The terms "acceptable," and "rational" did not appear in our decision tree analysis because of its design. However, a logistic regression we ran separately showed that these two descriptions are positively correlated with accepting the offer.

13 These terms did not appear in our decision tree analysis because of its design. However, a logistic regression we ran separately showed that these three descriptions are positively correlated with accepting the offer.

${ }^{14}$ The sense of fairness may have evolved as a way of dealing with the free-loader problem, some argue there is a cheater detection module (Cosmides and Tooby, 1992) while others emphasize the role of cooperation in building domestic and social organizations (Sterelny, 2016; Asma \& Gabriel, 2019). 
contextual factors. We were not able to tease out more implicit forms of empathy, viz. emotional contagion, with these tests, in the future we will consider using a face-to-face dyadic paradigm so that the tasks take on a more embodied interactive tone which we predict will enable closer manipulation of implicit forms of empathy.

\section{References}

Asma, S. T. \& Gabriel, R. (2019). The Emotional Mind: The Affective Roots of Culture and Cognition. Cambridge, MA: Harvard University Press.

Bosman, R., Sonnemans, J. \& Zeelenberg, M. (2001). Emotions, rejections, and cooling off in the Ultimatum Game. Working paper, University of Amsterdam.

Cappelen, A. W., Astri D. H., Erik, Ø. S. \& Bertil, T. (2007). The Pluralism of Fairness Ideals: An Experimental Approach. American Economic Review, 97(3), 818-27.

Christov-Moore, L., Simpson, E. A., Coudé, G., Grigaityte, K., Iacoboni, M. \& Ferrari, P. F. (2014). Empathy: Gender effects in brain and behavior. Neuroscience and biobehavioral reviews, 46(4), 604-627.

Côté, S., Piff, P. K. \& Willer, R. (2013). For whom do the ends justify the means? Social class and utilitarian moral judgment. Journal of personality and social psychology, 104(3), 490.

Decety, J. \& Michalska, K. J. (2010). Neurodevelopmental changes in the circuits underlying empathy and sympathy from childhood to adulthood. Developmental Science, 13(6), 886-899.

Damasio, A. R. (1994). Descartes' error: emotion, reason, and the human brain. New York: G.P. Putnam,

Davis, M. H. (1983). Measuring individual differences in empathy: Evidence for a multidimensional approach. Journal of Personality and Social Psychology, 44, 113-126.

Decety, J. (2007). A social cognitive neuroscience model of human empathy, in Fundamentals of Social Neuroscience, ed. E. Harmon-Jones and P. Winkielman. New York: Guilford Press.

Decety, J. \& Jackson, P. L. (2004). The functional architecture of human empathy. Behavioral and Cognitive Neuroscience Reviews, 3, 71-100.

Decety, J. \& Cowell, J. M. (2014). The complex relation between morality and empathy. Trends in Cognitive Sciences, 18(7), 337-339.

De Oliveira-Souza, R., Zhan, R. \& Moll, J. (2014). Neural Correlates of human morality: An overview. In Decety, J. \& Wheatley, T. (Eds.), The Moral brain, a multidisciplinary perspective (pp. 183-195). Cambridge, MA.: MIT Press.

de Waal, F. B. M. (1996). Good Natured: The Origins of Right and Wrong in Humans and Other Animals (Cambridge, MA: Harvard University Press).

de Waal, F. B. M. (2007). The 'Russian doll' model of empathy and imitation. In S. Bråten (Ed.), Advances in consciousness research: Vol. 68. On being moved: From mirror neurons to empathy (pp. 49-69). Amsterdam, Netherlands: John Benjamins Publishing Company.

Dunbar, R. I. M. (1998). The social brain hypothesis. Evol Anthropol, 6, 178-190.

Efferson, C., Lalive, R. \& Fehr, E. (2008). The Coevolution of Cultural Groups and Ingroup Favoritism. Science, 321(5897), 1844-1849.

Faravelli, M. (2007). How Context Matters: A Survey Based Experiment on Distributive Justice. Journal of Public Economics, 91(7-8), 1399-1422.

Fong, C. M. (2007). Evidence from an Experiment on Charity to Welfare Recipients: Reciprocity, Altruism and the Empathic Responsiveness Hypothesis. The Economic Journal, 117(522), 1008-24.

Forsyth, D. (2019). Making Moral Judgments: Psychological Perspectives on Morality, Ethics, and Decisionmaking. Routledge.

Frohlich, N., Joe A., Oppenheimer C, L. \& Eavey. (1987). Choices of Principles of Distributive Justice in Experimental Groups. American Journal of Political Science, 31(3), 606.

Heberlein, A. S. \& Saxe, R. R. (2005). Dissociation between emotion and personality judgments: Convergent evidence from functional neuroimaging. Neuroimage, 28, 770-777.

Hoffman, E., Matthew, L. \& Spitzer. (1985). Entitlements, Rights, and Fairness: An Experimental Examination of Subjects' Concepts of Distributive Justice. The Journal of Legal Studies, 14(2), 259-97.

Houser, D. \& McCabe, K. (2014). Experimental economics and experimental game theory. In Neuroeconomics (pp. 19-34). Academic Press.

Kandel, E. \& Edward, P. (1992). Peer Pressure and Partnerships. Journal of Political Economy, 100(August 1992), 801-17. 
Kirman, A. \& Miriam, T. (2010). Selfish or Selfless? The Role of Empathy in Economics. Philosophical Transactions of the Royal Society B: Biological Sciences, 365(1538), 303-17.

Klimecki, O. M., Sarah, V., Mayer, A. J., Jonathan, S. \& Michael, S. (2016). Empathy Promotes Altruistic Behavior in Economic Interactions. Scientific Reports, 6(1), 1-5.

Lawler, E. J., Shane, R. \& Thye, J. Y. (2008). Social Exchange and Micro Social Order. American Sociological Review, 73(4), 519-42.

Page, K. (2002). Empathy Leads to Fairness. Bulletin of Mathematical Biology, 64(6), 1101-16.

Preston, S. D. \& de Waal, F. B. M. (2002). Empathy: Its ultimate and proximate bases. Behavioral \& Brain Sciences, 25, 1-72.

Sautter, J. A., Levente, L. \& Brennen, B. (2007). A Dual-Edged Sword: Empathy and Collective Action in the Prisoner's Dilemma. The ANNALS of the American Academy of Political and Social Science, 614(1), 154-71.

Singer, T. \& Ernst, F. (2005). The Neuroeconomics of Mind Reading and Empathy. American Economic Review, 95(2), 340-45.

Stark, 0. \& Ita, F. (2000). Transfers, Empathy Formation, and Reverse Transfers. In The Economics of Reciprocity, Giving and Altruism, edited by L. A. Gérard-Varet, S. C. Kolm, and J. Mercier Ythier, 17481. London: Palgrave Macmillan UK.

Sterelny, K. (2016). Cooperation, Culture, and Conflict, British Journal for the Philosophy of Science, 67(1), 3158.

Strayer, J. (1987). Affective and cognitive processes in empathy. In N. Eisenberg \& J. Strayer (Eds.), Empathy and its development (pp. 218- 244). New York, NY: Cambridge University Press.

Singer, P. (ed.) (1977). Animal Liberation. NY: Avon Books.

Cosmides, L. \& Tooby, J. (1992). Cognitive adaptations for social exchange. In J. H. Barkow, L. Cosmides, \& J. Tooby (Eds.), The adapted mind: Evolutionary psychology and the generation of culture (p. 163228). Oxford University Press.

Thompson, E. (2005). Empathy and human experience, in Science, Religion, and the Human Experience, ed. J.D. Proctor (New York: Oxford University Press).

Zahavi, D. (2014). Empathy and Other-Directed Intentionality, Topoi, 33, 129-142.

\section{Appendix: Table 5: Hypothetical Scenarios}

\section{Case 1}

Suppose John and Jane are building a bike together. Assume that bike parts are given to them for free. Once finished, they will have to decide how many hours per week each should keep the bike.

Only other piece of information other information given is that Jane has put in more effort into the building of the bike than John has?

(One week $=168$ hours)

Which of the following distribution would be the fairest?

- 84 hours each

- Jane receives 126 hours and Jake receives 58 hours

- Jane receives 100 hours and Jake receives 84 hours

- Jane receives 92 hours and

\section{Case 2}

Imagine you participate in an ultimatum game. In the ultimatum game, there are two players who interact only once. There is no bargaining. The first player, the proposer, received a $\$ 100$ which had not been earned by the proposer. The proposer now offers a split of this sum between himself/herself and the second player (e.g. 60-40). The second player, the receiver, is communicated the information of this proposal and has to decide to reject or accept this division offered by the proposer. You play the role of the receiver in this game.

If you reject the offer, neither party gets anything. If you accept the offer, the first player gets his/her demand and you get the

\section{Case 3}

Is it fair for a hardware store to raise the price of snow shovels in anticipation of a spring snowstorm when supplies of shovels are low?

a. Yes

b. No

c. Fairness does not apply in this scenario 
Jake receives 76 hours

- Jane receives 68 hours and Jake receives 100 hours

You were told that John's lower effort was caused by the familial obligations to which he had to attend. In the light of this new piece of information, which of the following distribution would be the fairest?

- 84 hours each

- Jane receives 126 hours and Jake receives 58 hours

- Jane receives 100 hours and Jake receives 84 hours

- Jane receives 92 hours and Jake receives 76 hours

- Jane receives 76 hours and Jake receives 92 hours amount you were offered. You have been offered $\$ 1$. (This means the proposer demands \$99.)

Would you take it?

- Yes

- No

How would you describe the offer made by the first player? You can choose multiple answers.

- Fair

- Acceptable

- Rational

- Mutually beneficial

- Opportunistic

- Unfair

- Unwise

How would you describe your feelings if you were to receive this offer? You can choose multiple answers.

- Neutral

- $\quad$ Pleased

- Angry

- Jealous

- Frustrated

- Sad

- Surprised

- None of the above 